\title{
Surgery in very low birthweight infants
}

Fewer than one per cent of infants are born weighing less than $1500 \mathrm{~g}$, but a number of these very low birthweight infants are born with a correctable, congenital malformation which requires urgent surgery. A proportion of the others survive to develop surgical problems such as necrotising enterocolitis or symptomatic patent ductus arteriosus. The numbers of such infants in either group in published series are, however, small. ${ }^{1-4}$

The outlook for very low birthweight infants has improved greatly in the past 20 years. ${ }^{5}$ At present about $80 \%$ of these infants will be discharged from hospital $;{ }^{6}$ most deaths occur in those less than $1000 \mathrm{~g}$ birthweight of whom about 50 to $60 \%$ may be expected to survive. ${ }^{67}$ Thus, an increasing number of very low birthweight infants are now surviving and the number who eventually require surgery is also increasing.

Surgical conditions encountered in very low birthweight infants

Congenital conditions. The more common malformations encountered in term infants such as tracheo-oesophageal abnormalities, intestinal atresias, and abdominal wall defects, are also encountered in very low birthweight infants. For some reason Hirschsprung's disease seems to be very rare in these infants. However, meconium obstruction not associated with cystic fibrosis occurs more often in tiny babies. ${ }^{8}$

Acquired conditions. Most very low birthweight infants who progress to surgery do so as a result of acquired conditions. Necrotising enterocolitis occurs in more than six per cent. ${ }^{9}$ Ligation of patent ductus arteriosus is probably the most commonly performed surgical procedure at this birthweight, ${ }^{3}$ and some infants may require surgery for both conditions. Other acquired disorders such as hydrocephalus and gastro-oesophageal reflux also come to surgery, although not often in the neonatal period.

\section{Results of surgery}

In 1953 Gross and Ferguson ${ }^{10}$ reported on the surgical management of 159 preterm babies over a 16 year period. The average birthweight of these infants was $1900 \mathrm{~g}$, the smallest weighing just over $1000 \mathrm{~g}$, and the overall survival rate was $54 \%$. Apart from the principles of surgical management, almost everything else in the care of preterm babies has changed since that time.

Congenital conditions. Rickham ${ }^{1}$ reported five survivors of six infants of birthweight less than $1350 \mathrm{~g}$ who presented with tracheo-oesophageal abnormalities. The single death was attributed to an inappropriate operation. More recently Seashore et $a l^{3}$ reported survival in four of five infants with congenital abnormalities. Correction of major abnormalities is, therefore, feasible in the very low birthweight infant.

Acquired conditions. Larger numbers are encountered in this group of disorders. Survival rates in necrotising enterocolitis vary: Seashore $e t a l^{3}$ reported a $70 \%$ survival rate, which is about the average for larger series which include heavier babies; ${ }^{9}$ Kliegman et al ${ }^{11}$ report a $52 \%$ mortality in 40 very low birthweight infants with this disorder, but the number who had operations and the survival rate in these babies was not mentioned.

Ligation of patent ductus arteriosus is associated with a very low operative mortality, although death from other causes occurs in 20 to $30 \% .^{2}{ }^{3}$

\section{Review of mortality}

In the publications noted above the mortality rate ranges from $19 \%$ in a group of 64 very low birth weight infants ${ }^{3}$ to $42 \%$ in a group of 20 infants who weighed less than $1100 \mathrm{~g}$ at birth. ${ }^{4}$ Patent ductus arteriosus and necrotising enterocolitis were the conditions most commonly requiring surgery in these series. In each case the authors noted that the mortality rates were similar to those among infants of the same birthweight in the same hospitals who did not undergo surgery. In Bell's series ${ }^{4}$ the average age at operation was 30 days, by which time most deaths in 'non-surgical' babies will have occurred. Seashore $\mathrm{et} \mathrm{al}^{3}$ do not give the average age at operation but note that many of the sick infants will have succumbed from respiratory failure before developing necrotising enterocolitis or congestive cardiac failure. Smith $e t a l^{2}$ noted an average age of 30 days at the time of operation and the operative mortality was zero.

It is clear that major surgery may be undertaken with relatively low morbidity and mortality. Deaths have been due mainly to respiratory failure, sepsis, and other complications of extreme prematurity. ${ }^{2-4}$ 
Our own experience at the Hospital for Sick Children, Great Ormond Street is probably representative of the results achieved by other paediatric surgical centres in this country. In the four years from 1980 to 1983,52 very low birthweight infants were admitted under the care of the general surgeons. None was admitted for ligation of patent ductus arteriosus, although a few eventually required this operation. The largest group was those with congenital abnormalities (27) followed by those with necrotising enterocolitis (21). Excluding infants with lethal abnormalities (Potter's and Patau's syndromes, tracheal agenesis) the overall survival rate was $69 \%$. Fifty five per cent of those who weighed less than $1000 \mathrm{~g}$ at birth survived.

Which conditions require immediate, early, or delayed referral?

The following are guidelines only, as many factors will need to be considered before referral. A telephone consultation with the surgeon will probably yield the best results on the timing of transfer.

(1) Immediate referral-gastroschisis, ruptured exomphalos, tracheo-oesophageal abnormalities, perforations, and severe necrotising enterocolitis need an urgent surgical opinion.

(2) Early referral-intestinal atresia, imperforate anus, and symptomatic patent ductus arteriosus can usually wait for 24 hours.

(3) Delayed referral-intact exomphalos, inguinal hernias, unilateral renal masses, and most tumours can await clinical stability before referral.

The list is not comprehensive and the groupings are not rigid. Simply stated, urgent surgery in the first group is likely to yield the best results and may have little to offer in the last group.

\section{Conclusions}

Improved survival of very low birthweight infants has increased the number who will ultimately need an operation. Major surgery is feasible, and most infants survive operation. Timely surgical consultation is likely to yield optimal results.

\section{References}

1 Rickham PP. Infants with esophageal atresia weighing under 3 pounds. J Pediatr Surg 1981:16:595-8.

2 Smith DRS, Cook DH, Izukawa T, Trusler GA. Swyer PR. Rowe RD. Surgical management of patent ductus arteriosus in newborn infants of low birthweights. Arch Dis Child 1981:56:436-9.

${ }^{3}$ Seashore JH, Touloukian RJ, Kopf GS. Major surgery in infants weighing less than 1,500 grams. Am $J$ Surg 1983;145:483-7.

+ Bell MJ. Maurer MM, Bower RJ, Ternberg JL. Surgical mortality and morbidity in extremely low birthweight infants. Am J Dis Child 1983:137:682-4.

5 Stewart AL, Reynolds EOR, Lipscomb AP. Outcome for infants of very low birthweight: survey of world literature. Lancet $1981 ; \mathbf{i}: 1038-41$

- Yu VYH, Zhao SM, Bajuk B. Results of intensive care for 375 very low birthweight infants. Aust Paediatr J 1982:18:188-92.

${ }^{7}$ Barson AJ. Tasker M. Lieberman BA. Hillier VF. Impact of improved perinatal care on the causes of death. Arch Dis Child 1984:59:199-207.

* Vinograd I, Mogle P. Peleg O. Alpan G. Lernau OZ. Meconium disease in premature infants with very low birthweight. J Pediatr 1983;103:963-6.

"Stoll BJ, Kanto WP. Glass RI, Nahmias AJ, Brann AW. Epidemiology of necrotizing enterocolitis: a case control study. J Pediatr 1980:96:447-51.

11" Gross RE. Ferguson CC. Surgery in premature babies. Surg Gynecol Obstet 1953:95:631-41.

"Kliegman RM. Hack M, Jones P. Fanaroff AA. Epidemiologic study of necrotizing enterocolitis among low birthweight infants. Absence of identifiable risk factors. J Pediatr 1982;100:440-4.

E M KIELY Hospital for Sick Children, Great Ormond Street, London $W C 2 N 3 \mathrm{JH}$ 